\title{
Pai syndrome: first reported case in Qatar and review of literature of previously published cases
}

\author{
Mohamed Abdelmaaboud, ${ }^{1}$ Nuha Nimeri ${ }^{2}$ \\ ${ }^{1}$ NICU Women's Hospital, Hamad Medical Corporation, Doha, Qatar \\ ${ }^{2}$ Neonatal Research Fellowship Program, NICU Women's Hospital, Hamad Medical Corporation, Doha, Oatar \\ Correspondence to Dr Nuha Nimeri, uha@usa.net
}

\begin{abstract}
Summary
A full-term male baby born with severe complete median cleft lip and palate and multiple facial cutaneous polyps on the right nostril, left and right ears and angle of the mouth. Eye fundus examination revealed hypopigmented fundi, pigmented rings around both discs and hypopigmented maculae. Neurological, Cardiovascular and abdominal examination was unremarkable, with normal echocardiography and abdominal ultrasound. CT and MRI of the brain revealed hypogenesis of the corpus callosum and midline paracallosal lipomas and calcifications. Chromosomal study showed normal male 46, XY karyotype. This is the first reported case in Qatar and the second case in a patient of Arabian descent.
\end{abstract}

\section{BACKGROUND}

Pai syndrome (PS) was first described in 1987 as a constellation of three developmental anomalies:

(1) Complete median cleft palate (2) cutaneous polyps and (3) midline lipomas of the central nervous system. ${ }^{1}$ Since then, 18 cases have been reported by Pai et al (1987), ${ }^{1}$ Preece et al (1988), ${ }^{2}$ Morgan and Evans (1990), ${ }^{3}$ Rudnikschoneborn and Zerres (1994), ${ }^{4}$ Mishima et al (1999), ${ }^{5}$ Al-Mazrou et al (2001), ${ }^{6}$ Coban et al (2003), ${ }^{7}$ Szeto et al (2005), ${ }^{8}$ Guion-Almeida et al $(2007)^{9}$ and Castori et al (2007), ${ }^{10}$ Vaccarella et al (2008), ${ }^{11}$ Chousta et al $(2008)^{12}$ and Ochoa et al (2010). ${ }^{13}$ To our knowledge, this is the first case of PS to be reported in Qatar and the second case in a patient of Arabian descent. The aim of this report is to describe the clinical presentation of a new variant of PS with novel ocular findings of hypopigmented fundi and maculae together with pigmented discs.

\section{CASE PRESENTATION}

A full-term Qatari male was born by normal vaginal delivery to a 27-year-old primigravida of a non-consanguineous Qatari couple. There was no family history of any congenital anomalies. His birth weight and head circumference were in the 50th centile. Delivery was uncomplicated with
Apgar score 9 and 10 at 1 and 5 min, respectively. The baby was admitted to the Intermediate Care Unit, Women's Hospital, Hamad Medical Corporation, Qatar due to severe cleft lip and palate. The cleft of the upper lip and palate was detected antenatally at 25.3 weeks of gestational age, confirmed by scanning in the Fetomaternal unit. No other gross anomalies were detected.

On examination, the baby had severe complete median cleft lip and palate with multiple facial cutaneous polyps on the right nostril, left and right ears and angle of the mouth. Fundus examination revealed hypopigmented fundi, pigmented rings around both discs and hypopigmented maculae. Neurological, cardiovascular, abdominal and genitourinary examination was normal (figures 1 and 2).

\section{INVESTIGATIONS}

- Normal male karyotyping (46 XY)

- Normal Microarray and DNA banking done

- Normal Echocardiography

- Normal abdominal ultrasound

Ultrasound of the brain showed mineralising vasculopathy suggestive of TORCH infection excluded by negative laboratory investigations.
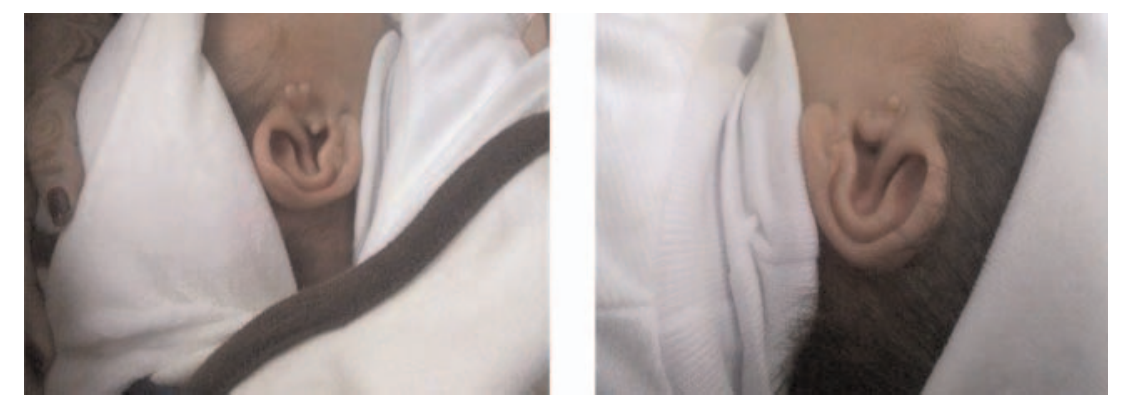

Figure 1 Clinical view of the patient at third month of age showing facial cutaneous polyps on the left and right ears. 


\section{BMJ Case Reports}
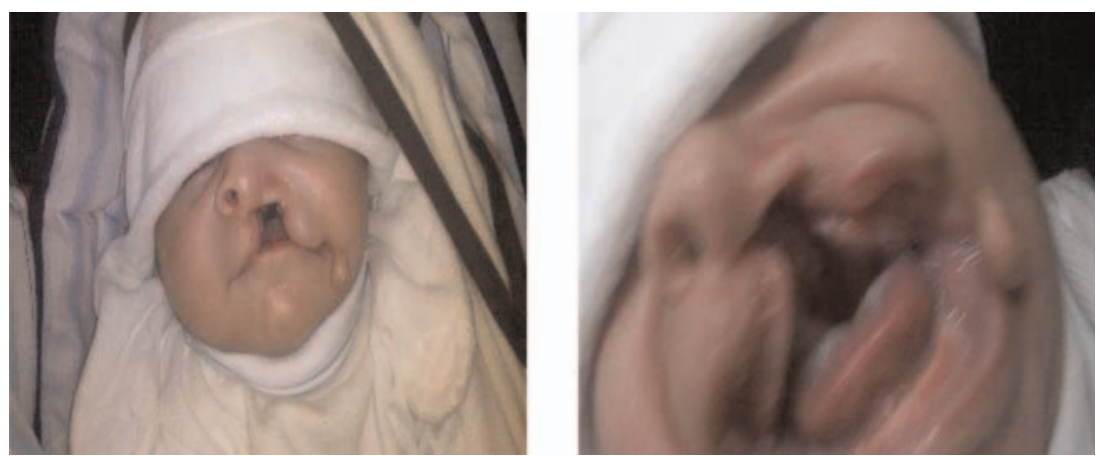

Figure 2 Clinical view of the patient showing severe complete median cleft lip and palate with facial cutaneous polyps on the right nostril and angle of the mouth.

CT of the head showed midline calcification with abnormal fat density in the frontal region, right lateral ventricle is distended; features are suggestive of midline brain anomaly (figures 3 and 4).

MRI of the head showed hypogenesis of corpus callosum, midline paracallosal calcifications and lipomas (figures 5 and 6).

\section{DIFFERENTIAL DIAGNOSIS}

Midline cleft of the upper lip is as rare as an isolated finding, and is more commonly found in association with other anomalies or as part of a recognised syndrome. A search conducted in the London Dysmorphology Database for median cleft of the upper lip; showed 40 possible syndromes such as holoprosencephaly, oral-facial-digital syndromes I and II, Ellis-van Creveld and Clefting-premaxilla agenesis among several other clefting syndromes.

\section{TREATMENT}

Skin polyp related to the right nostril was resected surgically and sent for histopathology that revealed a fibroepithelial polyp.

The cardiology team assessed the baby and they reported normal cardiovascular system.

The genetic team assessed the baby and suggested PS as the main differential. Maxillofacial surgery team assessed the baby for future surgical intervention.

An occupational therapist assessed the baby and reported no difficulties in feeding with Hypermann nipple.

\section{OUTCOME AND FOLLOW-UP}

No problems encountered with feeding. Motor and mental developments were normal for his age. The maxillofacial surgery, ophthalmology and genetic teams are following the case.

\section{DISCUSSION}

In 1987, GS Pai ${ }^{1}$ described an unusual combination of three rare congenital anomalies including complete median cleft lip, cutaneous polyps, calcification and lipomas of the corpus callosum. The baby's mother shows antimongoloid slant to her palperbral fissures and CT scan evidence of asymptomatic hydrocephalus. ${ }^{1}$ Since then, many variants of the syndrome were described. In 1988, Preece et $a l^{2}$ presented a 1-month-old infant with anomalies similar to Pai's description, in addition to dysgenesis of the anterior segment of the left eye. In 1994, Rudnik-Schoneborn and Zerres ${ }^{4}$ described a case with skin tag on the forehead, downward slanting palperbral fissure, bifid uvula and high plate associated with main elements of PS. Other variants included tongue like alopecia of the anterior frontal hairline and bifid nose as reported by Coban et $a l^{7}$ and Guion-Almeida et al. ${ }^{9}$

Up to date, there has been only one reported case of ocular abnormality as an additional finding of the expression of PS. Mishima et $a l^{5}$ described the presence of a conjunctive lipoma in the right eye, which was on the same side as the nasal polypoid skin mass. However, in our patient, hypopigmentation of the fundi and maculae was
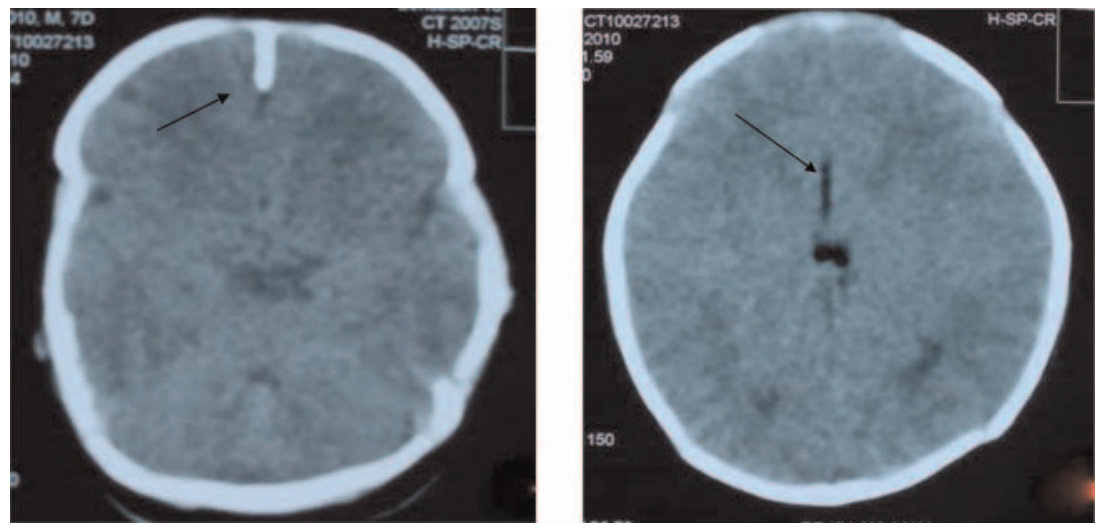

Figure 3 CT brain of the patient showing (A) midline calcification and (B) fat density in the frontal region. 


\section{BMJ Case Reports}

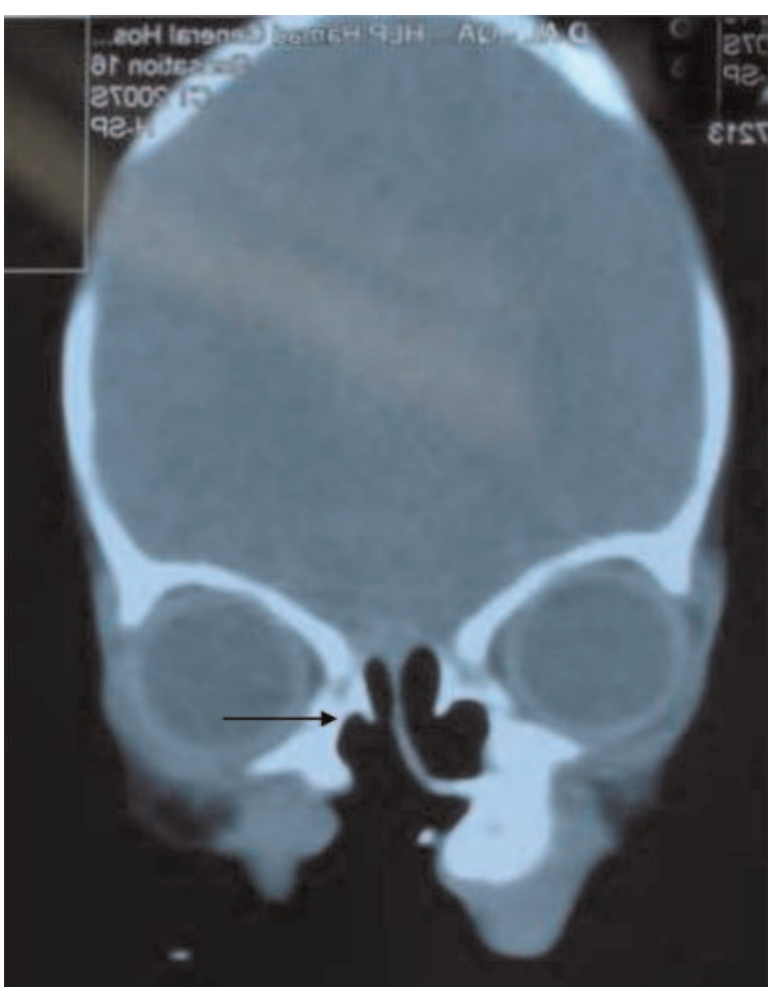

Figure 4 CT scan showing severe complete median cleft lip and palate.

seen in both eyes. To our knowledge, this variant of ocular anomalies has not been reported previously.

Currently, only two cases regarding prenatal diagnosis of PS have been reported. ${ }^{14}{ }^{15}$ The features reported included cleft lip and palate, cutaneous polyps and lipoma of the corpus callosum. Although our patient did exhibit features of median cleft lip and palate on fetal ultrasound

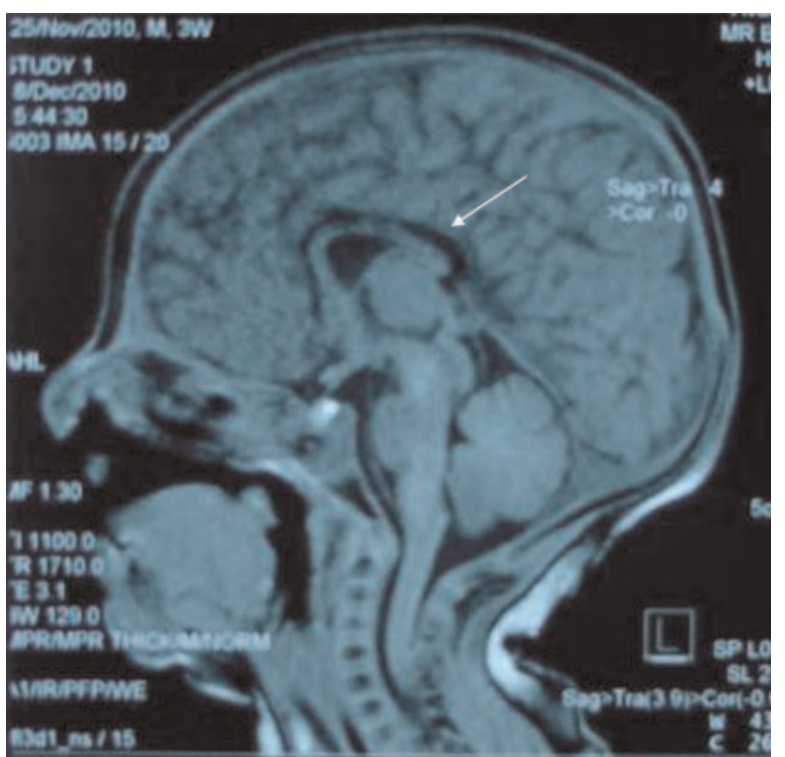

Figure 5 Sagittal Section in Brain MRI showing hypogenesis of corpus callosum.

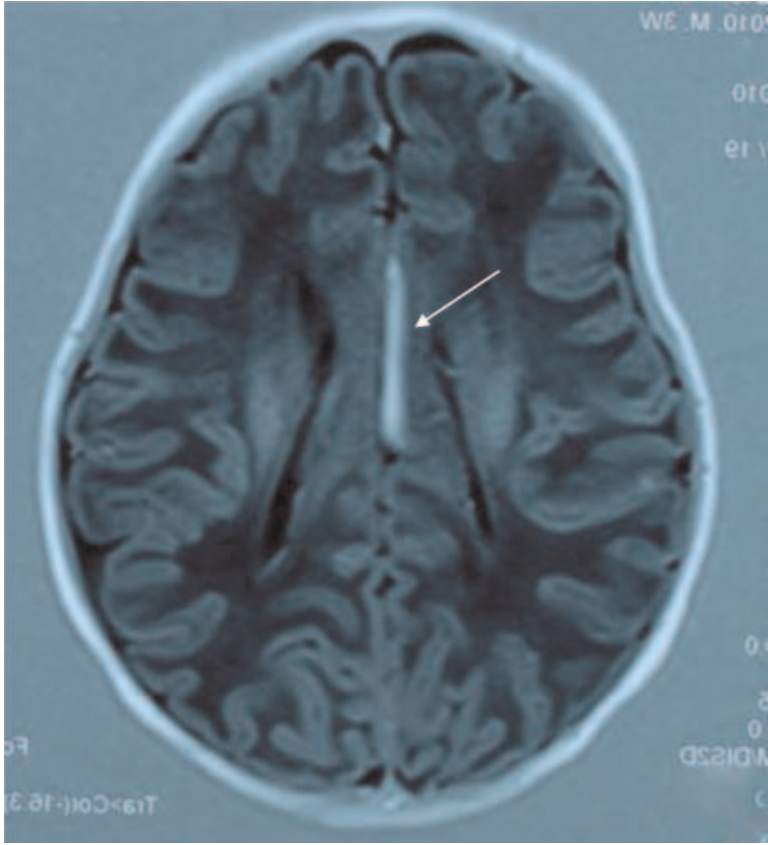

Figure 6 MRI of the brain showing midline paracallosal calcifications.

at 25 weeks plus 3 days of gestational age, the other anomalies were not detected until after birth.

The underlying pathophysiology remains unknown; however, several embryological theories have been proposed to explain the pathogenesis of these fibroepthilial polyps. Clusters of epitheial cells might have become sequestered during the fusion of the frontonasal processes. ${ }^{16}$ Another explanation was that the failure to obliterate an early embryological communication between an outpouching of dura and nasal tissue leads to an ectodermal residue. ${ }^{17}$ Consequently, the midline cleft may occur as a secondary event to the presence of nasal dermoid. ${ }^{14}$ On the other hand, Stark et $a l^{16}$ suggest that the midline cleft is the primary event, which occurs due to failure of mesodermal migration or inadequate consolidation of the median nasal process. As a result, the fibroepithelial polyps develop due to excessive mesodermal tissue in the oral cavity. ${ }^{18}$

The aetiology of PS continues to be debatable. Autosomal dominant inheritance was first suggested by Rudnik-Schoneborne and Zerres ${ }^{4}$ who described a patient with a median cleft lip, facial polyps and lipoma of the corpus callosum, whose father had similar facial dysmorphism and coloboma of the right iris. However, coloboma has never been previously reported and may not be part of the syndrome. ${ }^{5}$ It was concluded that a common genetic defect in mesodermal differentiation might be the underlying aetiology. This was supported by a report about a family in which five generations have been affected by these midline anomalies with variable expression. ${ }^{10}$ Knowing that the incidence of PS is much higher in men than in women, $\mathrm{X}$ linked recessive inheritance cannot be excluded. ${ }^{5}$ Furthermore, the karyotype of the proband of one patient with PS revealed a reciprocal translocation, 46, X, t (X; 16) (q28; q11.2), which was proposed as a candidate region for the gene responsible for the 


\section{BMJ Case Reports}

anomalies. ${ }^{5}$ However, it is argued that this proband may not had PS because she did not have lipomas in the corpus callosum, which is one of the main characteristics of Pai's. ${ }^{8}$ Our patient's chromosomal studies showed normal XY karyotype, and normal microarray. This supports the theory that the underlying aetiology can be multifactorial, as suggested by many case reports, which also found normal karyotype. ${ }^{6-9}$ 16-19 Also many authors suggested an underlying multi-factorial aetiology; supported by the discordance between monozygous twins in one previously reported case in Saudi Arabia. ${ }^{6}$ However, one of the defining features as described by Pai, that is, median cleft lip was not seen in that patient. Therefore, it can be argued that the patient may have not had PS.

\section{Learning points}

Pai syndrome (PS) is a rare combination of developmental anomalies, mainly median cleft lip, cutaneous facial polyps and midline lipomas in the central nervous system.

- Many variations of the expression of PS exist including bifid nose, ocular anomalies and tongue like alopecia of the anterior frontal hairline.

- Pathogenesis involves a defect in mesodermal differentiation and migration.

- Inheritance is still debatable. Some studies suggest autosomal-dominant inheritance, while others suggest $\mathrm{X}$ linked recessive or multifactorial aetiology.

\section{REFERENCES}

1. Pai GS, Levkoff AH, Leithiser RE Jr. Median cleft of the upper lip associated with lipomas of the central nervous system and cutaneous polyps. Am J Med Genet 1987;921-4.

2. Preece JM, Kearns DB, Wickersham JK, et al. Nasal Lipoma. J Laryngol Otol 1988;1044-6.

3. Morgan DW, Evans JN. Developmental nasal anomalies. J Laryngol Otol 1990;394-403.

4. Runik-Shoneborn S, Zerres K. A further patient with Pai syndrome with autosomal dominant inheritance? J Med Genet 1994;497-8.

5. Mishima K, Mori Y, Minami K, et al. A case of Pai Syndrome. Plast Reconstr Surg 1999;166-70.

6. Al-Mazrou KA, Al-Rekabi A, Alorainy IA, et al. Pai syndrome: a report of a case and review of the literature. Int J Pediatr Othorinolaryngol 2001;149-53.

7. Coban YK, Boran C, Omeroglu SA, et al. Pai syndrome: an adult patient with bifid nose and frontal hairline marker. Cleft Palate Craniofac J 2003;325-8.

8. Szeto C, Tewfik TL, Jewer D, et al. Pai syndrome (median cleft palate, cutaneous nasal polyp, and midline lipoma of the corpus callosum): a case report and literature review. Int J Pediatr Otorhinolaryngol 2005;1247-52.

9. Guion-Almeida ML, Mellado C, Beltrán C, et al. Pai syndrome: Report of seven South American patients. Am J Med Genet A 2007;3273-9.

10. Castori M, Rinaldi R, Bianchi $A$, et al. Pai syndrome: first patient with agenesis of the corpus callosum and literature review. Birth Defects Res $A$ Clin Mol Teratol 2007;673-9.

11. Vaccarella F, Pini Prato A, Fasciolo A, et al. Phenotypic variability of Pai syndrome: report of two patients and review of the literature. Int J Oral Maxillofac Surg 2008;1059-64.

12. Chousta A. Pericallosal lipoma associated with Pai syndrome: prenatal imaging findings. Ultrasound Obstet Gynecol 2008;708-10.

13. Ochoa J. P09.04: Prenatal diagnosis of Pai syndrome. Ultrasound Obstet Gynecol 2010:201.

14. Nakamura J, Tomonari $\mathrm{H}$, Goto S. True median cleft of the upper lip associated with three pedunculated club-shaped skin masses. Plast Reconstr Surg 1985;727-31.

15. Masuno M, Imaizum K, Fukushima $Y$, et al. Median cleft of the upper lip and pedunculated skin masses associated with the novo reciprocal translocation 46,X,t(X;16)(q28;q11.2). J Med Genet 1997;952-4.

16. Stark RB. The pathogenesis of harelip and cleft palate. Plast Reconstr Surg $1954 ; 20$

17. Pratt LW. Midline cyst of the nasal dorsum: embryologic origin and treatment. Laryngoscope 1965;968-75.

18. Sessions RB. Nasal dermal sinuses: new concepts and explanations. Laryngoscope 1982;1-28.

19. Lees MM, Connell F, Kangesu L, et al. Midline cleft lip and nasal dermoids over five generations: A distinct entity or autosomal dominant Pai syndrome? Clin Dysmorphol 2006;155-9.

\section{Patient consent Obtained}

This pdf has been created automatically from the final edited text and images.

Copyright 2012 BMJ Publishing Group. All rights reserved. For permission to reuse any of this content visit

http://group.bmj.com/group/rights-licensing/permissions.

BMJ Case Report Fellows may re-use this article for personal use and teaching without any further permission.

Please cite this article as follows (you will need to access the article online to obtain the date of publication).

Abdelmaaboud M, Nimeri N. Pai syndrome: first reported case in Qatar and review of literature of previously published cases. BMJ Case Reports 2012;10.1136/bcr-02-2012-5940, Published XXX

Become a Fellow of BMJ Case Reports today and you can:

- Submit as many cases as you like

- Enjoy fast sympathetic peer review and rapid publication of accepted articles

- Access all the published articles

- Re-use any of the published material for personal use and teaching without further permission

For information on Institutional Fellowships contact consortiasales@bmjgroup.com

Visit casereports.bmi.com for more articles like this and to become a Fellow 